\title{
Smoking Cessation Care for People with a Mental Illness: Family Carer Expectations of Health and Community Services
}

\author{
Jacqueline M. Bailey, ${ }^{1,2}$ Paula M. Wye, ${ }^{1,2,3}$ Emily A. Stockings, ${ }^{1,4}$ Kate M. Bartlem, ${ }^{1,2,3}$ \\ Alexandra P. Metse, ${ }^{1,2}$ John H. Wiggers, ${ }^{2,3,5}$ and Jennifer A. Bowman ${ }^{1,2}$ \\ ${ }^{1}$ School of Psychology, Faculty of Science and Information Technology, The University of Newcastle, University Drive, Callaghan, \\ NSW, 2308, Australia \\ ${ }^{2}$ Hunter Medical Research Institute, Clinical Research Centre, Lot 1 Kookaburra Circuit, New Lambton Heights, NSW, 2305, \\ Australia \\ ${ }^{3}$ Population Health, Hunter New England Local Health District, Booth Building, Wallsend Health Services, Longworth Avenue, \\ Wallsend, NSW, 2287, Australia \\ ${ }^{4}$ National Drug and Alcohol Research Centre, The University of New South Wales, 22-32 King Street, Randwick, NSW, 2031, \\ Australia \\ ${ }^{5}$ School of Medicine and Public Health, Faculty of Health and Medicine, The University of Newcastle, University Drive, Callaghan, \\ NSW, 2308, Australia
}

\begin{abstract}
ntroduction: Smoking prevalence remains high among people with a mental illness, contributing to higher levels of morbidity and mortality. Health and community services are an opportune setting for the provision of smoking cessation care. Although family carers are acknowledged to play a critical role in supporting the care and assistance provided by such services to people with a mental illness, their expectations regarding the delivery of smoking cessation care have not been examined.

Aims: To explore family carer expectations of smoking cessation care provision by four types of health services, to clients with a mental illness, and factors associated with expectations.

Methods: A cross-sectional survey was conducted with carers of a person with a mental illness residing in New South Wales, Australia. Carers were surveyed regarding their expectations of smoking cessation care provision from four types of health services. Possible associations between carer expectation of smoking cessation care provision and socio-demographic and attitudinal variables were explored.

Results: Of 144 carers, the majority of carers considered that smoking cessation care should be provided by: mental health hospitals $(71.4 \%)$, community mental health services $(78.0 \%)$, general practice $(82.7 \%)$, and non-government organisations (56.6\%). The factor most consistently related to expectation of care was a belief that smoking cessation could positively impact mental health.

Conclusions: The majority of carers expected smoking cessation treatment to be provided by all services catering for people with a mental illness, reinforcing the appropriateness for such services to provide smoking cessation care for clients in an effective and systematic manner.
\end{abstract}

\section{Introduction}

People with a mental illness are significantly more likely to smoke tobacco and experience high levels of nicotine dependence than people without such an illness (Australian Institute of Health and Welfare [AIHW], 2011; de Leon \& Diaz, 2005; Diaz, 2006). Consequently, people with a mental illness have higher rates of smokingrelated morbidity and mortality (Kilbourne et al., 2009; Lawrence, Hancock, \& Kisely, 2013) and have been identified as a priority group for the reduction of smok- ing prevalence (American Psychiatric Association [APA], 1996; NSW Ministry of Health, 2012; Royal College of Physicians \& Royal College of Psychiatrists [RCP\&RCP], 2013). Targeted, tailored smoking cessation strategies in response to the special needs of this population are recommended (APA, 1996; Department of Health and Ageing, 2012; RCP\&RCP, 2013).

Smoke-free policies in health and community services highlight the need and opportunity for such services to support clients with a mental illness to stop smoking 
(Prochaska, 2010; Stockings et al., 2014). In Australia and elsewhere, guidelines recommend, and policies often require, specialist mental health services including public psychiatric inpatient facilities and community mental health services, to support smoking cessation for all patients who smoke and to provide smoke-free environments to address the needs of patients and staff (both smokers and non-smokers) (Government of South Australia, 2013; National Institute for Health and Care Excellence, 2013; NSW Ministry of Health, 2012). Similarly, clinical practise guidelines for general practise (GP) services, the most frequently utilised health service for mental health problems in Australia (AIHW, 2014), recommend the provision of smoking cessation care to all patients who are smokers (Raw, McNeill, \& West, 1998; Royal Australian College of General Practitioners, 2004). Non-government organisations (NGOs) also provide health and/or welfare support to people with a mental illness in the Australian context (National Health Workforce Planning and Research Collaboration, 2011), and have been suggested to be appropriate settings for the provision of smoking cessation care (Bonevski et al., 2011; Bryant, Bonevski, Paul, Hull, \& O'Brien, 2012; NSW Ministry of Health, 2012).

Despite commonly held misconceptions amongst mental health professionals that clients are not motivated, or willing to quit smoking, or that tobacco smoking may manage or reduce the symptoms of mental illness (Lawn, 2004; Price, Ambrosetti, Sidani, \& Price, 2007; RCP\&RCP, 2013; Wye et al., 2010b), recent research has indicated otherwise (RCP\&RCP, 2013; Stockings et al., 2013). Further, recent research suggests that smokers with a mental illnesss would find it acceptable to be provided with smoking cessation care by the health and community services they currently utilise for mental health care (Bartlem et al., 2015; Ferron, Brunette, He, McHugo, \& Drake, 2011; Stockings et al., 2013). A survey of 558 clients of community mental health services in Australia for example, found the majority reported that it was acceptable to be provided smoking cessation care from such services in the form of assessment (96\%), brief advice to quit (86\%), and referral (89\%) (Bartlem et al., 2015).

A holistic care delivery approach that engages a variety of stakeholders, including family and friend networks in the care of clients has been suggested to be central to the provision of quality mental health care generally (Bickerton, Hossack, \& Nair, 2007; National Mental Health Commission, 2014; Office of the Chief Psychiatrist, 2007) and smoking cessation care specifically (Steering Committee for the Review of Government Service Provision, 2013). This approach is in keeping with the central role that family carers (individuals who provide care and assistance without payment (NSW Department of Health, 2007)) are considered to play in the lives of people with a mental illness (Wood et al., 2013). A large proportion of people in developed countries have such a role (Collings, 2009; Sinha, 2013), with approximately 9 million people in the United States caring for a person with a mental illness
(AARP Public Policy Institute, 2015). In Australia, 15\% of the adult population (2.4 million people) are estimated to care for a person with a mental illness (Pirkis et al., 2010).

Given family carers' acknowledged role in the provision of care and support to people with a mental illness (Bickerton et al., 2007; National Mental Health Commission, 2014; Office of the Chief Psychiatrist, 2007), including substantial interaction with health and community services, alignment between the care delivered by services and family carer expectations of care is likely to positively impact outcomes for people with a mental illness (NSW Government, 2014). The delivery of smoking cessation care to people with a mental illness is consistently reported to be suboptimal in inpatient facilities (Prochaska, Gill, \& Hall, 2004; Stockings et al., 2015; Wye et al., 2010a), community mental health services (Bartlem et al., 2014; Greening, 2005), and by GPs (Lord, Malone, \& Mitchell, 2010; McKay-Brown et al., 2008). For example, a survey of 97 smokers in an Australian inpatient psychiatric facility with a smoke-free policy identified that only $36.1 \%$ received brief advice to quit smoking and just $19.8 \%$ received brief advice and optimal nicotine replacement therapy (Stockings et al., 2015).

To date, only two studies have explored family carer perspectives of smoking cessation care in mental health services. A small qualitative study of six family member perspectives' in New Zealand identified several key limitations in the delivery of smoking cessation care, including a lack of consistency of implementation; family inclusion; and information regarding the harms of tobacco and benefits of available cessation treatments, and impact of cessation on client mental distress (Missen, Brannelly, \& Newton-Howes, 2013). In addition, an Australian qualitative study of 12 family carers described that family carers reported suboptimal smoking cessation care from mental health services for smokers with a mental illness for whom they provided care (Lawn, McNaughton, \& Fuller, 2015). Given this limited evidence base, an exploratory study was conducted to:

1) Explore family carer: understanding of the relationships between smoking and mental health; views of smoking bans in specialist mental health treatment settings; and expectations of smoking cessation care provision across four types of health and community service settings.

2) Investigate the association between (i) sociodemographic characteristics of the carer and person with a mental illness, (ii) clinical and smoking characteristics of the person with a mental illness, and (iii) family carer perceptions of the relationship between smoking and mental health, and of smoking bans, and family carer expectations of smoking cessation care provision by four types of service settings. 


\section{Methods}

\section{Design and Setting}

A cross sectional study was undertaken in one nonmetropolitan region in New South Wales (NSW), Australia, July to November 2013.

The study was approved by the Hunter New England Human Research Ethics Committee (No. 13/06/19/5.11) and registered with the University of Newcastle's Human Research Ethics Committee (No. H-2013-0343).

\section{Participants and Recruitment}

Potential participants were sourced through members of a state-level non-government carer support organisation that provides support services, advocacy, training, and education to carers of people with a mental illness. The organisation had operated across the study region for approximately 10 years, in partnership with local mental health services, providing individual and group support (Schizophrenia Fellowship of NSW Inc., 2008). Any member of the public who was a carer of a person with a mental illness was able to join the organisation without cost as a source of support for their role as a carer. Eligibility criteria for inclusion in the study included being 18 years or older and identifying themselves as a family carer for someone with any mental illness who was also over 18 years.

Potential participants throughout the Hunter New England Local Health District were identified by the carer organisation based on members' previously recorded interest in participating in research. The carer organisation posted an invitation to participate in the study, information statement, survey instrument, and reply-paid envelope to all such listed members $(n=327)$. Additional participants $(n=56)$ were approached by members of the research team through attendance at carer support group meetings.

\section{Data Collection Procedures}

Participants could complete the questionnaire online or as a paper copy. On average, the survey took 28 minutes to complete.

\section{Measures}

All socio-demographic, clinical, and smoking characteristic items were adapted from previous research (Bartlem et al., 2015). Items detailing the perceived mental health effects of smoking, attitudes to smoking bans in specialist mental health services, and expectations of smoking cessation care provision were developed for the current study.

Socio-demographic, clinical, and smoking characteristics: Six items addressed the age, gender, employment, marital status, highest level of education achieved, and Aboriginal and/or Torres Strait Islander status of both the family carer and the person with a mental illness. Participants were also asked their postcode of residence.
Participants reported: the primary psychiatric diagnosis for the person that they cared for (schizophrenia, depression, anxiety disorder, panic disorder, bipolar disorder, post-traumatic stress disorder, eating disorder, personality disorder, dementia, unsure, other); for how many years they had been in a caring role with this person (years: less than one, 1 to 2,3 to 10,11 to 20 , more than 20 ); if they lived in the same residence as the person they cared for (yes, no, sometimes); and what their relationship was to that person (parent, partner, child, sibling, neighbour, friend, other).

Participants were asked whether they smoked any tobacco products, and whether the person they cared for smoked any such products (yes - daily, yes - at least once a week, yes - less than once a week, no - quit within the last four months, no - quit longer than four months ago, no - never smoked).

Perceived mental health effects of smoking: All participants were asked to respond to two items: 'To what extent do you think quitting smoking can have a positive impact on mental health?' and 'To what extent do you think smoking can have a negative impact on mental health?' (not at all, a little, moderately, very, unsure).

Attitudes to smoking bans in specialist mental health services: For both mental health hospitals and community mental health services, participants were asked to indicate their agreement or otherwise with the statement: 'total smoking bans in such services are a good thing' (five-point Likert-type scale, strongly agree to strongly disagree). Participants were informed that currently total smoking bans exist in all health care facilities including mental health facilities.

Expectations of smoking cessation care provision: Participants were asked one item for each of the services studied, if they thought mental health hospitals, community mental health services, GPs, and NGOs should provide smoking cessation care for people with a mental illness (yes, no, unsure). Participants were asked to complete the item considering people with a mental illness generally, without regard to the use or otherwise of that service by the particular person they cared for.

\section{Data Analysis}

SPSS version 19 (IBM, 2013) was used to analyse the data. Participant postcode was used to determine the geographic remoteness and socio-economic index of disadvantage of the area in which they resided (Australian $\mathrm{Bu}$ reau of Statistics, 2011; Department of Health and Aged Care, 2001). Response categories for socio-demographic, clinical, and smoking characteristics were collapsed to two or three categories as shown in Table 1. Items regarding expectations of smoking cessation care provision by the four health and community service settings were condensed to two categories (yes, no, or unsure).

Descriptive statistics were used to summarise sociodemographic characteristics, smoking status, and perceived effect of smoking on health, attitudes to smoking 
Table 1

Socio-demographic characteristics

\begin{tabular}{|c|c|c|c|c|}
\hline \multirow[b]{2}{*}{ Characteristic } & \multicolumn{2}{|c|}{ Carer $^{\dagger}$} & \multicolumn{2}{|c|}{$\begin{array}{c}\text { Person with Mental } \\
\text { Illness }{ }^{\dagger}\end{array}$} \\
\hline & $\%$ & $n$ & $\%$ & $n$ \\
\hline \multicolumn{5}{|l|}{ Carer age (Years) } \\
\hline $18-54$ & 24.3 & 35 & & \\
\hline $55-74$ & 63.9 & 92 & & \\
\hline 75 and over & 11.8 & 17 & & \\
\hline \multicolumn{5}{|l|}{ Person with mental illness age (Years) } \\
\hline $18-34$ & & & 40.3 & 58 \\
\hline $35-54$ & & & 46.5 & 67 \\
\hline 55 and over & & & 13.2 & 19 \\
\hline \multicolumn{5}{|l|}{ Gender } \\
\hline Male & 19.0 & 27 & 66.7 & 96 \\
\hline \multicolumn{5}{|l|}{ Employment status } \\
\hline In the workforce & 31.9 & 45 & 20.3 & 28 \\
\hline \multicolumn{5}{|l|}{ Ethnicity } \\
\hline Aboriginal and/or Torres Strait Islander origin & 3.6 & 5 & 4.4 & 6 \\
\hline \multicolumn{5}{|l|}{ Marital status } \\
\hline Married/ living together in a relationship & 73.4 & 105 & 25.9 & 36 \\
\hline \multicolumn{5}{|l|}{ Highest education Level } \\
\hline Less than 4 years high school completed & 19.6 & 28 & 22.6 & 31 \\
\hline 4 years high school completed & 21.0 & 30 & 21.2 & 29 \\
\hline More than 4 years high school completed & 59.4 & 85 & 56.2 & 77 \\
\hline \multicolumn{5}{|l|}{ Socio-economic index of disadvantage } \\
\hline Lowest tertile & 54.9 & 78 & & \\
\hline Middle/highest tertile & 45.1 & 64 & & \\
\hline \multicolumn{5}{|l|}{ Geographic remoteness } \\
\hline Major cities & 31.0 & 44 & & \\
\hline Regional & 54.2 & 77 & & \\
\hline Rural & 14.8 & 21 & & \\
\hline \multicolumn{5}{|l|}{ Years spent caring for the person with mental illness } \\
\hline 20 years or less & 70.4 & 100 & & \\
\hline More than 20 years & 29.6 & 42 & & \\
\hline \multicolumn{5}{|c|}{ Carer and person with mental illness living in the same residence } \\
\hline Yes & 52.4 & 75 & & \\
\hline \multicolumn{5}{|l|}{ Carer relationship to person with mental illness } \\
\hline Parent & 61.5 & 88 & & \\
\hline Other relation & 38.5 & 55 & & \\
\hline \multicolumn{5}{|l|}{ Psychiatric diagnosis } \\
\hline Schizophrenia & & & 39.1 & 56 \\
\hline Bipolar disorder & & & 21.8 & 31 \\
\hline Other diagnosis & & & 39.1 & 56 \\
\hline \multicolumn{5}{|l|}{ Smoking status } \\
\hline Smoker & 11.8 & 17 & 68.8 & 99 \\
\hline
\end{tabular}

Number of missing responses to items ranged between 1 and 8 . 
Table 2

Perceived health effects of smoking and attitudes towards smoking bans

Response

\begin{tabular}{|c|c|c|c|c|c|c|c|c|c|c|}
\hline Item & $\%$ & $n$ & $\%$ & $\mathrm{n}$ & $\%$ & $n$ & $\%$ & $n$ & $\%$ & $n$ \\
\hline & \multicolumn{2}{|c|}{ Very } & \multicolumn{2}{|c|}{ Moderately } & \multicolumn{2}{|c|}{ A little } & \multicolumn{2}{|c|}{ Not at all } & \multicolumn{2}{|c|}{ Unsure } \\
\hline Quitting smoking - positive influence on mental health & 61.9 & 86 & 14.3 & 20 & 7.2 & 10 & 5.8 & 8 & 10.8 & 15 \\
\hline \multirow[t]{2}{*}{ Smoking - negative influence on mental health } & 59.0 & 82 & 14.3 & 20 & 10.1 & 14 & 6.5 & 9 & 10.1 & 14 \\
\hline & \multicolumn{2}{|c|}{ Strongly agree } & \multicolumn{2}{|c|}{ Agree } & \multicolumn{2}{|c|}{ Unsure } & \multicolumn{2}{|c|}{ Disagree } & \multicolumn{2}{|c|}{ Strongly disagree } \\
\hline Smoking bans in mental health hospitals are a good thing & 37.9 & 53 & 12.9 & 18 & 22.8 & 32 & 15.7 & 22 & 10.7 & 15 \\
\hline Smoking bans in community mental health services are a good thing & 45.3 & 62 & 19.7 & 27 & 15.3 & 21 & 13.1 & 18 & 6.6 & 9 \\
\hline
\end{tabular}

bans, and participants' expectations of smoking cessation care provision.

Chi-square analyses were used to examine possible bivariate associations between all socio-demographic and participant attitudinal variables with participant expectations of smoking cessation care provision in each of the four service settings. Variables associated at $p<0.25$ were subsequently entered into backward stepwise logistic regression models to examine the independent association $(p<0.05)$ of socio-demographic and attitudinal variables with expectation of smoking cessation care provision in each of the four service settings, and in all four settings combined (five models total). Hosmer and Lemeshow (2000) recommend the use of this $p$-value ( $p<$ 0.25 ) as variables which may be of clinical relevance can be discounted using the more traditional levels of $p<0.05$.

The provision of smoking cessation care and the enforcement of smoke free environments within service settings have been implemented to reduce non-smokers' exposure to environmental tobacco smoke and remove the cues to smoke for non-smokers and former smokers, thus reducing the potential for uptake and relapse (Etter, Khan \& Etter, 2008). As the implementation of these measures therefore potentially effects all clients, the responses of all carers - regardless of the smoking status of the person they cared for-were included in all analyses in the present study.

\section{Results}

\section{Sample Characteristics}

Of 383 people invited to participate, 144 accepted (37.6\%). For most of the invitations (227), the invitee failed to respond to the invitation, and 12 were found to be ineligible after making contact with the research team (with two carers caring for a person under the age of 18 , and 10 carers no longer in a caring role for a person with a mental illness). A total of 46 participants completed the survey in a carer support group, 97 participants completed the posted survey, and one participant completed the survey online. Participants who completed the survey in a support group were more likely to be 75 years or older $(21.7 \%$ vs. $7.1 \%$, $p=0.005)$ and to live in a major city $(57.8 \%$ vs. $18.6 \%$, $p<0.001)$ than participants who completed the survey by post. Characteristics of the participant and the person they cared for are presented in Table 1.

\section{Smoking Status and Perceived Health Effects of Smoking}

The majority (68.8\%) of people being cared for were reported by participants to be smokers; and $11.8 \%$ of participants identified themselves as smokers. Irrespective of smoking status, $59.0 \%$ of participants thought smoking had a very negative impact on mental health, and $61.9 \%$ thought quitting smoking would have a very positive impact on mental health (Table 2).

\section{Attitudes to Smoking Bans}

Half of participants agreed or strongly agreed that total smoking bans within mental health hospitals were 'a good thing' (50.8\%), whilst almost two-thirds agreed/strongly agreed with this statement for community mental health services $(65.0 \%)$ (Table 2$)$.

\section{Expectations of Smoking Cessation Care Provision}

A majority of participants considered that mental health hospitals, community mental health services, GPs, and NGOs should provide smoking cessation care to people with a mental illness $(71.4 \%, 78.0 \%, 82.7 \%$, and $56.6 \%$, respectively). One-half of participants expected all four service settings to provide smoking cessation care to persons with a mental illness (50.4\%), with only $3.9 \%$ responding that none of the four service settings should provide such care.

\section{Associations Between Socio-Demographic and Attitudinal Variables, with Expectations of Smoking Cessation Care Provision}

Factors associated at $p<0.25$ that were entered into the logistic regressions are presented in Table 4 in the appendix. Participants holding the view that 'quitting smoking would have a very positive impact on mental health' had three-fold greater odds of expecting smoking cessation care to be provided in mental health hospitals [Odds Ratio (OR): 3.43 ] and community mental health services 


\section{Table 3}

Variables associated with carer expectations of smoking cessation care provision across health care settings

\begin{tabular}{|c|c|c|c|c|c|c|c|}
\hline Predictor & B & SE & OR & \multicolumn{2}{|c|}{ 95\% CI Lower upper } & $d f$ & $p$ \\
\hline \multicolumn{8}{|l|}{ Mental health hospitals $\ddagger(n=127)$} \\
\hline Carer age (18-54) & -2.052 & 0.909 & 0.129 & 0.022 & 0.763 & 1 & 0.024 \\
\hline Carer age (75 and over) & & & & & & & reference category \\
\hline Residing in the same residence & -0.940 & 0.441 & 0.391 & 0.165 & 0.928 & 1 & 0.033 \\
\hline Not or sometimes living in same residence & & & & & & & reference category \\
\hline Quitting smoking 'very' positive impact on mental health & 1.233 & 0.445 & 3.431 & 1.433 & 8.211 & 1 & $0.006^{*}$ \\
\hline $\begin{array}{l}\text { Quitting smoking 'moderate' 'a little' 'not at all' 'unsure' of } \\
\text { positive impact on mental health }\end{array}$ & & & & & & & reference category \\
\hline \multicolumn{8}{|l|}{ Community mental health services $\S(n=127)$} \\
\hline Carer education -4 years completed high school & -1.459 & 0.627 & 0.233 & 0.068 & 0.795 & 1 & 0.020 \\
\hline Carer education - Higher School Certificate or higher & & & & & & & reference category \\
\hline Lowest tertile & 1.284 & 0.539 & 3.611 & 1.255 & 10.386 & 1 & 0.017 \\
\hline Middle/highest tertile & & & & & & & reference category \\
\hline Residing in the same residence & -1.246 & 0.545 & 0.288 & 0.099 & 0.837 & 1 & 0.022 \\
\hline Not or sometimes living in same residence & & & & & & & reference category \\
\hline Quitting smoking 'very' positive impact on mental health & 1.254 & 0.528 & 3.503 & 1.245 & 9.857 & 1 & 0.018 \\
\hline $\begin{array}{l}\text { Quitting smoking 'moderate' 'a little' 'not at all' 'unsure' of } \\
\text { positive impact on mental health }\end{array}$ & & & & & & & reference category \\
\hline \multicolumn{8}{|l|}{$\operatorname{GPs}^{\Uparrow}(n=123)$} \\
\hline $\begin{array}{l}\text { Carer education - less than } 4 \text { years } \\
\text { completed high school }\end{array}$ & \multicolumn{6}{|c|}{ completed high school } & $0.001^{*}$ \\
\hline \multicolumn{8}{|l|}{ NGOs $\mathbf{s}^{\dagger \dagger}(n=124)$} \\
\hline Female gender of person being cared for & -0.881 & 0.419 & 0.414 & 0.182 & 0.942 & 1 & 0.036 \\
\hline Male gender of person being cared for & & & & & & & reference category \\
\hline Residing in the same residence & -0.896 & 0.415 & 0.408 & 0.181 & 0.921 & 1 & 0.031 \\
\hline Not or sometimes living in same residence & & & & & & & reference category \\
\hline Quitting smoking 'very' positive impact on mental health & 0.849 & 0.411 & 2.338 & 1.045 & 5.231 & 1 & 0.039 \\
\hline $\begin{array}{l}\text { Quitting smoking 'moderate' 'a little' 'not at all' 'unsure' of } \\
\text { positive impact on mental health }\end{array}$ & & & & & & & reference category \\
\hline \multicolumn{8}{|l|}{ All settings $\$ \ddagger(n=122)$} \\
\hline Quitting smoking 'very' positive impact on mental health & 0.760 & 0.377 & 2.139 & 1.022 & 4.478 & 1 & 0.044 \\
\hline $\begin{array}{l}\text { Quitting smoking 'moderate' 'a little' 'not at all' 'unsure' of } \\
\text { positive impact on mental health }\end{array}$ & & & & & & & reference category \\
\hline
\end{tabular}

* Significant at $p<0.01$

$\ddagger$ Variables entered into regression: carer age, living in the same residence, relationship, carer smoking status, impact of quitting smoking on mental health.

$\S$ Variables entered into regression: carer age, carer education, socio-economic disadvantage, years spent caring, living in the same residence, person with mental illness smoking

status, impact of quitting smoking on mental health.

"Variables entered into regression: person with mental illness employment status, person with mental illness ethnicity, carer education, years spent caring.

${ }^{\dagger}$ Variables entered into regression: person with mental illness age, person with mental illness gender, living in the same residence, impact of quitting smoking on mental health.

$\ddagger$ Variable entered into regression: person with mental illness gender, impact of quitting smoking on mental health.

(OR: 3.50) (Table 3). Similarly, participants holding this view were more than twice as likely to expect smoking cessation care to be provided by NGOs (OR: 2.34), and in each of the four service settings (OR: 2.14). The lowest tertile in the socio-economic index of disadvantage was associated with an increased expectation of care provision in community mental health services (OR: 3.61) compared to the middle/highest tertile.

Conversely, participants who resided with the person with a mental illness were less likely to expect smoking cessation care provision in mental health hospitals (OR: 0.39 ), community mental health services (OR: 0.29), and 
NGOs (OR: 0.41). Younger participant age (18-54) was associated with a decreased expectation of care in mental health hospitals (OR: 0.13). Lower participant education (where participants had completed 4 years of high school compared to participants who had completed the High School Certificate or higher education) was associated with a decreased expectation of care in community mental health services (OR: 0.23), and with a decreased expectation of care from GPs (OR: 0.15). Where the person with a mental illness being cared for was female, there was a decreased expectation of smoking cessation care from NGOs (OR: 0.41).

\section{Discussion}

Few studies have explored the views of family carers regarding the provision of smoking cessation care by health and community service settings to people with a mental illness, and this exploratory study is the first to do so quantitatively. The study identified that a large majority $(61.9 \%)$ of family carers believed that quitting smoking would have a positive impact on mental health, and the majority of carers expected health and community services to provide smoking cessation care $(56.6 \%-82.7 \%$, by setting); perceptions which may enhance receptivity to strategies to encourage smoking cessation by those they care for.

Half of the participants supported total smoking bans within specialist mental health settings, with approximately one-fifth 'unsure' about their benefits. Family carer support for total smoking bans is comparable to the level of support reported by mental health inpatient staff (54\%) and inpatients (46\%) in previous Australian research (Stockings et al., 2015; Wye et al., 2010); and consistent with carers previously identifying the appropriate opportunity to support smoking cessation amongst people with a mental illness that smoke-free policies within mental health services represent (Lawn et al., 2015; Missen et al., 2013). The sizeable proportion of participants that were 'unsure' of the benefits of smoking bans may have been influenced by a lack of knowledge or awareness of smoking bans and their implementation, as has been found in research conducted amongst mental health professionals (Lawn \& Campion, 2013; Lawn, 2004; Wye et al., 2010). Such findings emphasise the need to better consult with, inform, and educate family carers regarding the rationale for, and implementation of smoking bans; a desire expressed by family carers (Missen et al., 2013). In addition, these findings may be influenced by the inconsistent implementation of smoke-free policies within mental health settings (Missen et al., 2013; RCP\&RCP, 2013; Wye et al., 2010a; Wye et al., 2014), reducing the likelihood of intended benefits being achieved and hence experienced by carers.

The high prevalence of participant expectation that smoking cessation care should be provided across all of the settings investigated aligns with previous research con- ducted with family carers which identified an expectation that the smoking behaviours of the person with a mental illness should be addressed in mental and general health services they attended (Lawn et al., 2015; Missen et al., 2013). Similarly, previous studies of support by clinical staff for the provision of smoking cessation care in inpatient and community mental health services (Robson, Haddad, Gray, \& Gournay, 2013; Wye et al., 2010b), GPs (Holmberg et al., 2014), and NGOs (Bryant et al., 2012). A lesser proportion of participants expected smoking cessation care to be provided by NGOs, a finding that may reflect such services not having a direct focus on the provision of health-related care (Housego \& O'Brien, 2012).

When compared to the findings of studies of actual smoking cessation care provision, the current findings suggest a lack of alignment between the expectations of family carers - key stakeholders in the design and provision of mental health services (NSW Government, 2014; Office of the Chief Psychiatrist, 2007) - and the delivery of smoking cessation care. Despite the existence of guidelines, the literature indicates that smoking cessation care is not routinely provided to smokers with a mental illness in inpatient (Prochaska et al., 2004; Wye et al., 2010a) or community (Anderson et al., 2013; Bartlem et al., 2015; Bartlem et al., 2014) mental health services and smoking cessation supports such as Quitline referral and nicotine replacement therapy are not routinely provided (Anderson et al., 2013; Bartlem et al., 2015; Bartlem et al., 2014). In GP, suboptimal smoking cessation care has been reported to be provided to both general and mental health patients (Holmberg et al., 2014; Lord et al., 2010; McKayBrown et al., 2008).

A perception that smoking cessation could positively impact on mental health was the factor most consistently and strongly associated with the expectation of care being provided. Given that evidence of the benefits for mental health of quitting smoking is continuing to accrue (Lancet Editorial, 2013; RCP\&RCP, 2013; Taylor et al., 2014), further research is required to determine if dissemination of such information by health and community services to family carers may enhance their understanding of the need for smoking cessation care provision and related smoking bans.

Residing with the person they cared for was associated with lower family carer expectation of smoking cessation care being provided in three of the service settings studied. It may be that cohabiting family carers perceive less of a need for health and community services to provide such care, given their significant role in providing care generally. Previous research has suggested that cohabitating carers may decline the offer of various forms of care due to a perception that this may negatively impact on their being the primary caregiver (Harris, Diminic, Marshall, Stockings, \& Degenhardt, 2015; Malcolm, Rowlands, \& Inch, 1998). This remains speculative and other possibilities could have led to this result. It may also be, as described in Lawn et al. 
(2015), that cohabiting carers perceived the supply, distribution, and regulation of tobacco to the person they cared for as a part of their caring role despite the knowledge of the physical health risks associated with smoking. Carers may perceive a greater importance in monitoring a consistent tobacco consumption or encouraging a decrease in consumption as opposed to encouraging cessation (Lawn et al., 2015). Further research is required to gain a better understanding of this association. The findings of differences in associations across the service settings could also be further examined in future research with a larger and more generalisable sample.

Given the exploratory nature of the study, a number of study limitations need to be considered when interpreting its findings. First, the study sample involved family carers who were volunteer members of a carer support organisation within one local health district in NSW, Australia. The extent to which the participants' expectations and experiences are representative of all family carers is unknown. A broader study involving non self-selected carers across a broader geographic region would be of benefit. Second, the low study response rate suggests caution in interpreting the findings as they may not be representative of the family carer population from which they were recruited. Despite this, the demographic characteristics of the participants were largely consistent with the characteristics of carers in Australia (NSW Department of Health, 2007). Third, the study used carer reported smoking status of the person they care for as a measure of smoking status. The accuracy of such a measure is unknown; however, proxy measures of smoking behaviour generally have been found to be accurate (Amos, Hastings, Angus, Bostock, \& Fidler, 2009; Florescu et al., 2009). Fourth, the current study employed a 'general' focus of the items regarding expectations of smoking cessation care provision, regardless of service usage by the person being cared for; future research could explore potential differences between expectations focussing on service usage of the person with a mental illness. Finally, the survey explored carers' perceptions of the effects of smoking on the mental health of the person they cared for but did not explore the perceived physical health effects. Further research could explore the extent to which carers perceive a negative physical health effect of smoking; however, the limited research to date does suggest that carers are aware of the negative physical health consequences (Lawn, McNaughton, \& Fuller, 2015), as might be expected given the high levels of such awareness within the community generally (Mulshine \& Healton, 2014).

This study has highlighted the need to better understand the potential benefits of stronger engagement with and education of carers of people with a mental illness regarding the provision of smoking cessation care by health care services. Further research is required to confirm these findings and to explore how family carers may play a role in enhancing the effectiveness of smoking cessation care provided by health and community services.

\section{Acknowledgements}

The authors would like to thank all carer members of Carer Assist for their contribution to the project. The authors would also like to thank all Carer Assist team leaders, especially Sharon Freebody, for their assistance with participant recruitment.

\section{Financial Support}

This research received no specific grant from any funding agency, commercial, or not-for-profit sectors.

\section{Conflict of Interest}

\section{None.}

\section{Ethical Standards}

The authors assert that all procedures contributing to this work comply with the ethical standards of the relevant national and institutional committees on human experimentation and with the Helsinki Declaration of 1975, as revised in 2008 .

\section{Supplementary Material}

To view supplementary material for this article, please visit http://dx.doi.org/10.1017/jsc.2016.23.

\section{References}

AARP Public Policy Institute, N. A. f. C. (2015). Executive summary: Caregiving in the U.S. Chicago: AARP, NAC.

American Psychiatric Association. (1996). Practice guideline for the treatment of patients with nicotine dependence. The American Journal of Psychiatry, 153(10), 1-31.

Amos, A., Hastings, G., Angus, K., Bostock, Y., \& Fidler, J. (2009). A review of young people and smoking in England. Edinburgh: Public Health Research Consortium.

Anderson, A., Bowman, J., Knight, J., Wye, P., Terry, M., Grimshaw, S. et al. (2013). Smoking cessation care provision and support procedures in Australian community mental health services. Psychiatric Services, 64(7), 707-710. doi:10.1176/appi.ps.201200213.

Australian Bureau of Statistics. (2011). Technical paper. Socioeconomic indexes for areas (SEIFA). (2033.0.55.001). Canberra: Australian Bureau of Statistics.

Australian Institute of Health and Welfare. (2011). 2010 national drug strategy household survey report. Canberra: AIHW.

Australian Institute of Health and Welfare. (2014). Mental health services- in brief 2014. Canberra: AIHW.

Bartlem, K., Bowman, J., Freund, M., Wye, P., Lecathelinais, C., McElwaine, K. et al., (2015). Acceptability and receipt of preventive care for chronic-disease health risk behaviours reported by clients of community mental health services. Psychiatric Services, 66(8), 857-864. doi:10.1176/appi.ps.201400360

Bartlem, K., Bowman, J., Freund, M., Wye, P., McElwaine, K., Wolfenden, L. et al., (2014). Care provision to prevent chronic disease by community mental health clinicians. 
American Journal of Preventive Medicine, 47(6), 762-770. doi:10.1016/j.amepre.2014.08.003

Bickerton, A., Hossack, K., \& Nair, J. (2007). Working with families program. North Sydney: NSW Department of Health.

Bonevski, B., Paul, C., D’Este, C., Sanson-Fisher, R., West, R., Girgis, A. et al., (2011). RCT of a client-centred, caseworkerdelivered smoking cessation intervention for a socially disadvantaged population. BMC Public Health, 11(1), 70. doi:10.1186/1471-2458-11-70

Bryant, J., Bonevski, B., Paul, C., Hull, P., \& O’Brien, J. (2012). Implementing a smoking cessation program in social and community service organisations: A feasibility and acceptability trial. Drug Alcohol Review, 31(5), 678-684. doi:10.1111/j.1465-3362.2011.00391.x

Collings, S. (2009). Who cares for people with schizophrenia: Family carers' health, circumstances and adjustment. Wellington: University of Otago.

de Leon, J., \& Diaz, F. J. (2005). A meta-analysis of worldwide studies demonstrates an association between schizophrenia and tobacco smoking behaviors. Schizophrenia Research, 76(2-3), 135-157. doi:10.1016/j.schres.2005.02.010

Department of Health and Aged Care. (2001). Measuring remoteness: Accessibility/remoteness index of australia (ARIA). Occasional Papers: New Series Number 14. Canberra: Commonwealth of Australia.

Department of Health and Ageing. (2012). National tobacco strategy 2012-2018. Canberra: Commonwealth of Australia.

Diaz, F. J. R., Velasquez, D. M., Susce, M. T. \& de Leon, J. (2006). Smoking and smoking cessation among persons with severe mental illnesses. Psychiatric Services, 57(4), 462.

Etter, M., Khan, A. N., \& Etter, J. F. (2008). Acceptability and impact of a partial smoking ban followed by a total smoking ban in a psychiatric hospital. Preventive Medicine, 46, 572578. doi: 10.1016/j.ypmed.2008.01.004

Ferron, J. C., Brunette, M., He, X., McHugo, G., \& Drake, R. (2011). Course of smoking and quit attempts among clients with co-occurring severe mental illness and substance use disorders. Psychiatric Services, 62(4), 353-359.

Florescu, A., Ferrence, R., Einarson, T., Selby, P., Soldin, O., \& Koren, G. (2009). Methods for quantification of exposure to cigarette smoking and environmental tobacco smoke: Focus on developmental toxicology. Therapeutic Drug Monitoring, 31(1), 14-30. doi:10.1097/FTD.0b013e3181957a3b

Government of South Australia. (2013). South Australia health: Smoke-free policy. Adelaide: Government of South Australia.

Greening, J. (2005). Physical health of patients in rehabilitation and recovery: A survey of case note records. Psychiatric Bulletin, 29(6), 210-212. doi:10.1192/pb.29.6.210

Harris, M., Diminic, S., Marshall, C., Stockings, E., \& Degenhardt, L. (2015). Estimating service demand for respite care among informal carers of people with psychological disabilities in Australia. Aust NZJ Public Health, 39(3), 284-292. doi:10.1111/1753-6405.12337

Holmberg, C., Sarganas, G., Mittring, N., Braun, V., Dini, L., Heintze, C. et al., (2014). Primary prevention in general practice - views of German general practitioners:
A mixed-methods study. BMC Family Practice, 15, 103. doi:10.1186/1471-2296-15-103

Hosmer, D. W., \& Lemeshow, S. (2000). Applied logistic regression (2nd ed.). USA: John Wiley \& Sons

Housego, A., \& O’Brien, T. (2012). Delivery of public services by non-government organisations. Australian Journal of Public Administration, 71(2), 211-220. doi:10.1111/j.1467-8500.2012.00765.x

IBM. (2013). SPSS statistics (Version 22). Chicago, IL: SPSS Inc.

Kilbourne, A. M., Morden, N. E., Austin, K., Ilgen, M., McCarthy, J. F., Dalack, G. et al., (2009). Excess heartdisease-related mortality in a national study of patients with mental disorders: Identifying modifiable risk factors. General Hospital Psychiatry, 31(6), 555-563. doi:10.1016/j.genhosppsych.2009.07.008

Lancet Editorial. (2013). Smoke alarm: Mental illness and tobacco. The Lancet, 381(9872), 1071.

Lawn, S. J. (2004). Systemic barriers to quitting smoking among institutionalised public mental health service populations: A comparison of two Australian sites. International Journal of Social Psychiatry, 50(3), 204-215. doi:10.1177/0020764004043129

Lawn, S., \& Campion, J. (2013). Achieving smoke-free mental health services: Lessons from the past decade of implementation research. International Journal of Environmental Research and Public Health, 10(9), 4224-4244. doi:10.3390/ijerph10094224

Lawn, S., McNaughton, D., \& Fuller, L. (2015). What carers of family members with mental illness say, think and do about their relative's smoking and the implications for health promotion and service delivery: A qualitative study. International Journal of Mental Health Promotion, 17(5), 261-277. doi:10.1080/14623730.2015.1080462

Lawrence, D., Hancock, K., \& Kisely, S. (2013). The gap in life expectancy from preventable physical illness in psychiatric patients in Western Australia: Retrospective analysis of population based registers. BMJ, 346, f2539. doi:10.1136/bmj.f2539

Lord, O., Malone, D., \& Mitchell, A. J. (2010). Receipt of preventive medical care and medical screening for patients with mental illness: A comparative analysis. General Hospital Psychiatry, 32(5), 519-543. doi:10.1016/j.genhosppsych.2010.04.004

Malcolm, K., Rowlands, P., \& Inch, H. (1998). Assessment of respite needs for carers of persons with severe mental illness. Psychiatric Bulletin, 22(6), 354-355. doi:10.1192/pb.22.6.354

McKay-Brown, L., Bishop, N., Balmford, J., Borland, R., Kirby, C., \& Piterman, L. (2008). The impact of a GP clinical audit on the provision of smoking cessation advice. Asia Pacific Family Medicine, 7(1), 4. doi:10.1186/1447-056X-7-4

Missen, R. L., Brannelly, T., \& Newton-Howes, G. (2013). Qualitative exploration of family perspectives of smokefree mental health and addiction services. International Journal of Mental Health Nursing, 22(4), 294-303. doi:10.1111/j.1447-0349.2012.00882.x

Mulshine, J., \& Healton, C. (2014). Tobacco control since the 1964 surgeon general's report: Reflecting back and looking forward. Oncology, 86, 180-183. 
National Health Workforce Planning and Research Collaboration. (2011). Mental health non-government organisation workforce project final report. Adelaide: Health Workforce Australia.

National Institute for Health and Care Excellence. (2013). Smoking cessation in secondary care: Acute, maternity and mental health services. London: NICE.

National Mental Health Commission. (2014). The national review of mental health programmes and services. Sydney: NMHC.

New South Wales Government. (2014). NSW carers strategy 2014-2019. Sydney: New South Wales Government.

NSW Department of Health. (2007). NSW carers action plan 2007-2012 summary. North Sydney: NSW Department of Health.

NSW Ministry of Health. (2012). NSW tobacco strategy 20122017. North Sydney: NSW Health.

Office of the Chief Psychiatrist. (2007). Communicating with carers and families: Information sharing for better outcomes. Delivering a healthy WA. Perth: Government of Western Australia.

Pirkis, J., Burgess, P., Hardy, J., Harris, M., Slade, T., \& Johnston, A. (2010). Who cares? A profile of people who care for relatives with a mental disorder. Australian and New Zealand Journal of Psychiatry, 44, 929-937.

Price, J. H., Ambrosetti, L. M., Sidani, J. E., \& Price, J. A. (2007). Psychiatrists' smoking cessation activities with Ohio community mental health center patients. Community Mental Health Journal, 43(3), 251-266. doi:10.1007/s10597-006-9074-3

Prochaska, J. J. (2010). Integrating tobacco treatment into mental health settings. Journal of the American Medical Association, 304(22), 2534-2535.

Prochaska, J. J., Gill, P., \& Hall, S. M. (2004). Treatment of tobacco use in an inpatient psychiatric setting. Psychiatric Services, 55(11), 1265-1270.

Raw, M., McNeill, A., \& West, R. (1998). Smoking cessation guidelines for health professionals: A guide to effective smoking cessation interventions for the health care system. Thorax, 53(5), s1-s18.

Robson, D., Haddad, M., Gray, R., \& Gournay, K. (2013). Mental health nursing and physical health care: A cross-sectional study of nurses' attitudes, practice, and perceived training needs for the physical health care of people with severe mental illness. International Journal of Mental Health Nursing, 22(5), 409-417. doi:10.1111/j.1447-0349.2012.00883.x

Royal Australian College of General Practitioners. (2004). Smoking cessation guidelines for Australian general practice. Practice handbook. Canberra: Australian Government.

Royal College of Physicians, \& Royal College of Psychiatrists. (2013). Smoking and mental health. Royal College of Psychiatrists Council Report CR178. London: Royal College of Physicians.
Schizophrenia Fellowship of NSW Inc. (2008). Carer assist: Support for mental health carers. Retrieved from http://www.sfnsw.org.au/carer-assist/home/Home\#.VEg kxCukTU.

Sinha, M. (2013). Spotlight on Canadians: Results from the general social survey. Portrait of caregivers, 2012. Ottawa: Statistics Canada.

Steering Committee for the Review of Government Service Provision. (2013). Report on government services 2013. Canberra: Productivity Commission.

Stockings, E. A., Bowman, J. A., Bartlem, K. M., McElwaine, K. M., Baker, A. L., Terry, M. et al. (2015). Implementation of a smoke-free policy in an inpatient psychiatric facility: Patient-reported adherence, support, and receipt of nicotinedependence treatment. International Journal Mental Health Nursing , 24(4), 342-349. doi:10.1111/inm.12128

Stockings, E. A., Bowman, J. A., Prochaska, J. J., Baker, A. L., Clancy, R., Knight, J. et al., (2014). The impact of a smoke-free psychiatric hospitalization on patient smoking outcomes: A systematic review. Australian and New Zealand Journal of Psychiatry, 48(7), 617-633. doi:10.1177/0004867414533835

Stockings, E., Bowman, J., McElwaine, K., Baker, A., Terry, M., Clancy, R. et al., (2013). Readiness to quit smoking and quit attempts among Australian mental health inpatients. Nicotine Tobacco Research, 15(5), 942-949. doi:10.1093/ntr/nts206

Taylor, G., McNeill, A., Girling, A., Farley, A., Lindson-Hawley, N., \& Aveyard, P. (2014). Change in mental health after smoking cessation: Systematic review and meta-analysis. BMJ, 348, g1151. doi:10.1136/bmj.g1151

Wood, V. J., Curtis, S. E., Gesler, W., Spencer, I. H., Close, H. J., Mason, J. et al. (2013). Creating 'therapeutic landscapes' for mental health carers in inpatient settings: A dynamic perspective on permeability and inclusivity. Social Science Medicine, 91, 122-129. doi:10.1016/j.socscimed.2012.09.045

Wye, P., Bowman, J., Wiggers, J., Baker, A., Carr, V., Terry, M. et al., (2010b). Providing nicotine dependence treatment to psychiatric inpatients: The views of Australian nurse managers. Journal Psychiatric Mental Health Nursing, 17(4), 319327. doi:10.1111/j.1365-2850.2009.01524.x

Wye, P., Bowman, J., Wiggers, J., Baker, A., Carr, V., Terry, M. et al. (2010a). An audit of the prevalence of recorded nicotine dependence treatment in an Australian psychiatric hospital. Australian and New Zealand Journal of Public Health, 34(3), 298-303. doi:10.1111/j.1753-6405.2010.00530.x

Wye, P., Bowman, J., Wiggers, J., Baker, A., Knight, J., Carr, V. et al., (2010). Total smoking bans in psychiatric inpatient services: A survey of perceived benefits, barriers and support among staff. BMC Public Health, 10, 372. doi:10.1186/1471-2458-10-372

Wye, P., Gow, L., Constable, J., Bowman, J., Lawn, S., \& Wiggers, J. (2014). Observation of the extent of smoking in a mental health inpatient facility with a smoke-free policy. BMC Psychiatry, 14(94), 1-8. 